\title{
THE EFFECT OF STORAGE ON THE RADIOCARBON, STABLE CARBON AND NITROGEN ISOTOPIC SIGNATURES AND CONCENTRATIONS OF RIVERINE DOM
}

\author{
$\mathrm{P}_{\text {Gulliver }}^{1,2} \cdot \mathrm{S}$ Waldron ${ }^{3} \cdot \mathrm{E} \mathrm{M} \mathrm{Scott}^{4} \cdot \mathrm{C}$ L Bryant $^{1}$ \\ ABSTRACT. Chemical preservatives (e.g. mercuric chloride) are routinely added to freshwater samples to prevent biolog- \\ ical activity compromising the isotopic signature of dissolved organic matter (DOM) with time. However, alternative preser- \\ vation methods are needed due to regulations restricting the use of preservatives with potentially adverse environmental and \\ health impacts, rendering such additions unviable. This study investigates whether a non-chemical storage method is suffi- \\ cient to maintain the radiocarbon and stable carbon and nitrogen signatures of freshwater DOM from a low order river system \\ draining a peaty catchment. Some $50 \mathrm{~L}$ of stream water were collected in 1 plastic carbuoy and, within $24 \mathrm{hr}, 1-\mathrm{L}$ aliquots \\ were transferred to acid-washed plastic bottles. Five aliquots were analyzed immediately to determine the baseline values for \\ ${ }^{14} \mathrm{C}(\mathrm{pMC}), \delta^{13} \mathrm{C}(\mathrm{VPDB} \%), \delta^{15} \mathrm{~N}(\mathrm{AIR} \%), \% \mathrm{C}\left(\mathrm{mg} \mathrm{L}^{-1}\right)$, and $\% \mathrm{~N}\left(\mathrm{mg} \mathrm{L}^{-1}\right)$. Of the remaining subsamples, 20 were frozen and \\ a further 20 refrigerated at $<4^{\circ} \mathrm{C}$. After $7,30,90$, and 180 days, 5 frozen and 5 refrigerated aliquots were analyzed in the same \\ manner as the baseline aliquots. Analysis of the results shows that there is no statistically significant interaction between the \\ variables storage method or length of storage for any of the determinants. Storage method has a statistically significant effect \\ on ${ }^{14} \mathrm{C}(\mathrm{pMC})$ and $[\mathrm{C}]\left(\mathrm{mg} \mathrm{L}^{-1}\right)$. Length of storage has a statistically significant effect on $\delta^{13} \mathrm{C}$ ( $\left.\mathrm{vPDB} \%\right),[\mathrm{C}]\left(\mathrm{mg} \mathrm{L}^{-1}\right)$, and [N] \\ $\left(\mathrm{mg} \mathrm{L}^{-1}\right)$ values. Neither storage method nor length of storage appear to have a statistically significant effect on $\delta^{15} \mathrm{~N}\left({ }_{\mathrm{AIR}} \% \mathrm{o}\right)$ \\ values.
}

\section{INTRODUCTION}

Through the export of particulate and dissolved organic matter, wetlands and organic-rich soils exert a profound influence on the chemistry of water bodies draining them (Lobbes et al. 2000). Such drainage systems are particularly important in the Northern Hemisphere; for example, they are reported to be the single largest source of dissolved organic carbon (DOC) for export from the UK (Hope et al. 1997). Although humic substances are the major component of DOC in wetlands, a large proportion of wetland DOC is bioavailable, supporting elevated microbial activity (Zeigler and Fogel 2003). In addition to autochthonous production, riverine DOC will be comprised of such allochthonous material. Thus, environmental parameters influencing catchment productivity or discharge may lead to temporal and spatial variation in concentration and composition (isotopic and molecular) of riverine dissolved organic matter (DOM). How this material is processed within a river system is also fundamental to delineate the processes that shape carbon delivery to the oceanic environment, a growing and challenging area of research (Raymond and Bauer 2001; Amon and Meon 2004; Ahad et al. 2008; Griffith et al. 2009).

Further, the concentration of DOM in freshwater river systems is increasing (Monteith et al. 2007). Various reasons for this have been postulated, e.g. increase in temperature, decreasing acidity (Freeman et al. 2001; Evans et al. 2007). With strong evidence that the metabolism of terrestrially derived organic carbon within river systems is responsible for substantial $\mathrm{CO}_{2}$ outgassing to the atmosphere (Battin et al. 2008), increasing DOM concentrations could support increasing $\mathrm{CO}_{2}$ efflux from freshwater systems. Shaping that capacity though is the composition of the DOM: ecological stoichiometric theory predicts that the potential for DOC to be respired to $\mathrm{CO}_{2}$ will be less if nutrients $(\mathrm{N}, \mathrm{P})$ are available for biomass production; without such nutrients, maintenance respiration is more

\footnotetext{
${ }^{1}$ Natural Environment Research Council, Radiocarbon Facility (Environment) NRCF(E), East Kilbride G75 0QF, Scotland. ${ }^{2}$ Department of Statistics, University of Glasgow G12 8QW, Scotland.

${ }^{3}$ Department of Geographical and Earth Sciences, University of Glasgow, Glasgow G12 8QQ, Scotland.

${ }^{4}$ Corresponding author. Email: P.Gulliver@nercrcl.gla.ac.uk.
}

(C) 2010 by the Arizona Board of Regents on behalf of the University of Arizona Proceedings of the 20th International Radiocarbon Conference, edited by A J T Jull RADIOCARBON, Vol 52, Nr 2-3, 2010, p 1113-1122 
likely. Thus, studies investigating both carbon and nutrient cycling and export are becoming more widespread (e.g. Zeigler et al. 2003; Amon and Meon 2004; Waldron et al. 2009).

In contrast to stoichiometric and stable isotope analysis, ${ }^{14} \mathrm{C}$ analysis requires relatively large volumes of sample water $(\sim 1 \mathrm{~L})$ for extraction of sufficient DOC. To collect sufficient samples for detailed studies, particularly in remote locations, requires considerable investment in collection and transport, and thus maintaining sample integrity after collection is paramount. Further, with the move towards combined biogeochemical studies, such preservation should not compromise multiple elemental assays.

Historically, maintaining sample integrity has been undertaken by 1) cold storage combined with light exclusion, 2) freezing, and 3) chemical preservation (or poisoning). All methods have limitations:

- 1) and 2): Storage of large volumes of chilled or frozen water presents field (i.e. the site may be remote; access to a power supply is limited and laboratory logistical problems (storage of such large volumes). For dark, cold storage, light exclusion prevents photosynthesis; however, this method does not stop respiration and indeed often the biological community is adapted to low temperatures. Until fully frozen, respiration may occur as enzymatic activity persists in the liquid phase. Therefore, when stored cold or frozen the compositional structure of the DOM pool may change with time and not be representative of sample composition at collection.

- 3) This can be overcome by addition of a chemical preservative that fully inhibits biological activity, e.g. mercuric chloride, sodium azide, formalin, mixed antibiotics, or chloroform. Mercuric chloride has been historically popular for studies involving carbon and nitrogen analysis (partly because only small amounts are needed and the compound does not contain carbon or nitrogen), but growing concerns about its highly poisonous nature and environmental impact upon disposal, in conjunction with the additional resources necessary to process poisoned samples (e.g. time dedicated to safety assessments, additional laboratory procedures, and equipment to implement the devised safety plan) are such that many organizations and laboratories (including the UK's Natural Environment Research Council Radiocarbon Facility, Environment (NRCF(E)), where the majority of sample processing was carried out) avoid the use of $\mathrm{HgCl}_{2}$. Further, where the preservative contains $\mathrm{N}, \mathrm{S}$, or $\mathrm{P}$, this may compromise paired $\mathrm{C}$ and nutrient analysis.

As such, we carried out the following study to investigate the effect of light-excluded cold storage and freezing on the carbon and nitrogen isotopic and stoichiometric composition of fluvial DOM parameters considered to offer insight on source and subsequent reworking. Specifically, we wished to address the following questions:

1. Do samples need to be frozen or will cold storage suffice?

2. Is there an optimum length of time beyond which cold/frozen storage is unsuitable?

3. Are all determinants susceptible to storage effects?

\section{METHODS AND MATERIALS}

Some $50 \mathrm{~L}$ of streamwater were collected in a master reservoir from Brocky Burn on 10 October 2004. Brocky Burn is an upland headwater stream in Glen Dye $\left(56^{\circ} 56^{\prime} 27^{\prime \prime} \mathrm{N}, 2^{\circ} 36^{\prime} 00^{\prime \prime} \mathrm{W}\right)$, in turn a subcatchment of the River Dee in NE Scotland, which discharges into the North Sea. Brocky Burn drains $1.3 \mathrm{~km}^{2}$ of peats and peaty podzols underlain by granite. In the catchment, bracken coexists with heather and there is little riparian vegetation. Regular burning of small areas of moorland may 
have contributed to some peat degradation and hagging (Thompson et al. 2001) and in places erosion extends to the organomineral interface. A high density of ephemeral drainage channels cover the peat, connecting it to the perennial stream channel network. Detailed diagrams of topography, soil coverage, geology, and land use of the Glen Dye catchment are available (Waldron et al. 2009).

The master reservoir sample was dispensed into 45 one-liter polyethylene storage bottles, previously cleaned by acid-washing with $5 \mathrm{M} \mathrm{HNO}_{3}$, prior to rinsing with copious quantities of deionized water. Of the 45 samples, 5 bottles, randomly chosen, were immediately processed to provide baseline values for comparison with stored samples (these represent streamwater composition within 36 $\mathrm{hr}$ of collection). Contemporaneously, 20 samples each were immediately dark refrigerated $\left(4^{\circ} \mathrm{C}\right)$ or frozen $\left(-10^{\circ} \mathrm{C}\right)$ until later analysis. To assess whether leaching of "dead" carbon from the storage bottles (composed of fossil-fuel-derived polyethylene) could compromise the interpretation, 1-L aliquots of ultrapure deionized water were refrigerated and frozen along with the sample aliquots and to which a modern ${ }^{14} \mathrm{C}$ standard was added later.

Subsequently, 5 refrigerated and 5 frozen streamwaters, and 1 refrigerated and 1 frozen ultrapure water aliquot were processed on days 7, 30, 90, and 180 after collection. Frozen samples were defrosted on the day of processing. After removal from storage, samples were filtered through precombusted $\left(4 \mathrm{hr}\right.$ at $\left.400{ }^{\circ} \mathrm{C}\right) 0.7-\mu \mathrm{m} \mathrm{GF} / \mathrm{F}$. Measured volumes of filtered sample were rotary-evaporated $\left(40{ }^{\circ} \mathrm{C} ; 50 \mathrm{mbar}\right)$, until a few $\mathrm{mL}$ of solution remained. Filtered field samples were not acidified prior to DOM concentration as the $\mathrm{pH}$ of the streamwater when sampled was 5.4, and inorganic carbon would be mostly present as $\mathrm{CO}_{2}$ and removed during rotary evaporation.

Approximately $50 \mathrm{mg}$ of TIRI Barleymash, an international ${ }^{14} \mathrm{C}$ reference material with a consensus value of $116.35 \pm 0.008 \mathrm{pMC}$ (Gulliksen and Scott 1995) was added to the rotary-evaporated deionized water prior to freeze-drying. This concentrate was quantitatively transferred to preweighed, glass beakers and freeze-dried, and the resultant solid homogenized. All glassware used in sample processing at $\mathrm{NRCF}(\mathrm{E})$ was acid-washed in $\left(5 \mathrm{M} \mathrm{HNO}_{3}\right)$ prior to use.

For ${ }^{14} \mathrm{C}(\mathrm{pMC})$ and $\delta^{13} \mathrm{C}(\mathrm{vPDB} \%$ ) analysis, a known weight of the extracted DOM was heated with $\mathrm{CuO}$ in an evacuated sealed quartz tube (Boutton et al. 1983). The $\mathrm{CO}_{2}$ generated was cryogenically purified and the volume recorded before the gas was collected in aliquots. One aliquot was converted to graphite by $\mathrm{Fe} / \mathrm{Zn}$ reduction and the resultant graphite analyzed for ${ }^{14} \mathrm{C}$ content at the Scottish Universities Environmental Research Centre (SUERC) AMS laboratory using a NEC 5MV accelerator mass spectrometer ( $\mathrm{Xu}$ et al. 2004). A further aliquot was analyzed for $\delta^{13} \mathrm{C}$ VPDB $\%$ using a dual-inlet stable isotope mass spectrometer (VG OPTIMA). Isotope ratios were corrected using the procedure outlined by Craig (1957) and are reported in per mil relative to the international reference standard Vienna Pee Dee Belemnite (VPDB) (Coplen 1994).

$\delta^{15} \mathrm{~N}_{\mathrm{AIR}} \%$ and $\mathrm{wt} \% \mathrm{~N}$ of total dissolved nitrogen (TDN) were assayed by analysis of $\sim 2 \mathrm{mg}$ of freeze-dried DOM at the SUERC on a Costech C/N/S analyzer, linked to a ThermoFinnigan continuous-flow mass spectrometer (CF-IRMS).

$\% \mathrm{C}$ and $\mathrm{N}$ were calculated assuming quantitative conversion of a known mass of DOM during

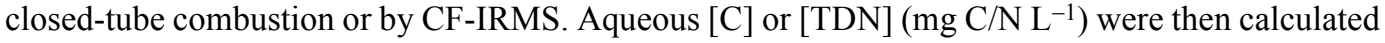
from mass DOM recovered and knowledge of sample volume.

In keeping with international practice, ${ }^{14} \mathrm{C}$ results have been corrected to a $\delta^{13} \mathrm{C}_{\mathrm{VPDB}}$ value of $-25 \%$ using the $\delta^{13} \mathrm{C}$ of each sample and are reported as percent modern carbon (pMC) with $\pm 1-\sigma$ level for overall analytical confidence (Stuiver and Polach 1977; Mook and van der Plicht 1999). Quoted precision for ${ }^{14} \mathrm{C}$ values analysis is $4 \%$ (Freeman et al. 2007). Repeat analysis of an internal standard 
reveals long-term precision in $\delta^{13} \mathrm{C}_{\mathrm{VPDB}}$ and $\delta^{15} \mathrm{~N}_{\mathrm{AIR}}$ is $0.1 \%$ and $\leq 0.3 \%$, respectively. Statistical analysis was carried using a general linear model in Minitab ${ }^{\circledR} 15$ software (www.minitab.com).

\section{RESULTS AND DISCUSSION}

Here, we focus primarily on comparison of the storage methods with minor interpretation of sample composition. Baseline means for ${ }^{14} \mathrm{C}, \delta^{13} \mathrm{C}, \delta^{15} \mathrm{~N},[\mathrm{C}]$, and [N] were calculated from the 5 samples processed immediately (Table 1 ). ${ }^{14} \mathrm{C}_{\mathrm{DOC}}$ values range from 108.53 to $109.30 \mathrm{pMC}$. All samples were $>100 \mathrm{pMC}$, showing that the majority of the carbon present in the DOC has been fixed in the past $50 \mathrm{yr} . \delta^{13} \mathrm{C}_{\mathrm{DOC}}$ values range from -28.2 to $-28.0 \%$ and are within the range typical of terrestrially derived carbon, suggesting that the DOC is of dominantly allochthonous origin. This is supported by $\delta^{15} \mathrm{~N}_{\mathrm{TDN}}(+0.1 \%$ to $+2.4 \%$ ), which has low values, typical of terrestrial organic matter (e.g. Norra et al. 2005). The large range in $\delta^{15} \mathrm{~N}_{\text {TDN }}$ likely reflects an inorganic contribution, which given the low organic $\mathrm{N}$ concentrations, can lead to variation in $\delta^{15} \mathrm{~N}$ due to sparse distribution. [C] values ranged from 19.3 to $20.6 \mathrm{mg} \mathrm{L}^{-1} \mathrm{C}$, while all $5[\mathrm{~N}]$ analyses gave a result of $0.5 \mathrm{mg} \mathrm{N} \mathrm{L}^{-1}$.

Table 1 Summary statistics for baseline samples $(n=5)$.

\begin{tabular}{lllll}
\hline Determinant & Mean & $\begin{array}{l}\text { Standard } \\
\text { deviation }\end{array}$ & $\begin{array}{l}\text { Standard } \\
\text { error }\end{array}$ & $\begin{array}{l}\text { Prediction } \\
\text { error }^{\mathrm{a}}\end{array}$ \\
\hline${ }^{14} \mathrm{C}(\mathrm{pMC})$ & 109.11 & 0.33 & 0.15 & 0.36 \\
$\delta^{13} \mathrm{C} \% \mathrm{o}_{(\mathrm{VPB})}$ & -28.14 & 0.06 & 0.04 & 0.07 \\
$\delta^{15} \mathrm{~N} \% \mathrm{o}_{\mathrm{AIR}}$ & +1.12 & 0.85 & 0.38 & 0.94 \\
{$[\mathrm{C}]\left(\mathrm{mg} \mathrm{L}^{-1}\right)$} & 19.82 & 0.58 & 0.26 & 0.64 \\
{$[\mathrm{~N}]\left(\mathrm{mg} \mathrm{L}^{-1}\right)$} & 0.49 & 0.03 & 0.01 & 0.03 \\
\hline
\end{tabular}

aPrediction error calculated as follows: PI $=\left[2 * \sqrt{ } \sigma^{2} *(1+(1 / n)]\right.$, where $\sigma$ is the standard deviation of the mean and $n=$ number of analyses.

Table 2a Summary statistics for refrigerated samples.

\begin{tabular}{lrll|rll|rll|rl|rl|}
\hline & \multicolumn{3}{c|}{ Day 7 } & \multicolumn{3}{c|}{ Day 30 } & \multicolumn{3}{c}{ Day 90 } & \multicolumn{3}{c}{ Day 180 } \\
\cline { 2 - 13 } Determinant & Mean & SE & SD & Mean & SE & SD & Mean & SE & SD & Mean & SE & SD \\
\hline${ }^{14} \mathrm{C}(\mathrm{pMC})$ & 109.08 & 0.13 & 0.30 & 109.03 & 0.21 & 0.47 & 109.23 & 0.13 & 0.30 & 108.53 & 0.29 & 0.65 \\
$\left.\delta^{13} \mathrm{C}_{\text {(VPDB }}\right)$ & -28.22 & 0.02 & 0.04 & -28.22 & 0.04 & 0.08 & -28.12 & 0.02 & 0.04 & -27.66 & 0.10 & 0.22 \\
$\delta^{15} \mathrm{No}_{\text {AIR }}$ & +0.48 & 0.29 & 0.64 & +0.22 & 0.19 & 0.42 & +0.54 & 0.62 & 1.39 & +0.22 & 0.34 & 0.77 \\
{$[\mathrm{C}]\left(\mathrm{mg} \mathrm{L}^{-1}\right)$} & 18.99 & 0.23 & 0.51 & 19.36 & 0.64 & 1.44 & 16.39 & 1.57 & 3.50 & 18.07 & 0.22 & 0.50 \\
{$[\mathrm{~N}]\left(\mathrm{mg} \mathrm{L}^{-1}\right)$} & 0.47 & 0.03 & 0.07 & 0.56 & 0.01 & 0.02 & 0.72 & 0.13 & 0.30 & 0.53 & 0.06 & 0.14 \\
\hline
\end{tabular}

Table $2 b$ Summary statistics for frozen samples.

\begin{tabular}{|c|c|c|c|c|c|c|c|c|c|c|c|c|}
\hline \multirow[b]{2}{*}{ Determinant } & \multicolumn{3}{|c|}{ Day 7} & \multicolumn{3}{|c|}{ Day 30} & \multicolumn{3}{|c|}{ Day 90} & \multicolumn{3}{|c|}{ Day 180} \\
\hline & Mean & $\mathrm{SE}$ & SD & Mean & SE & $\mathrm{SD}$ & Mean & $\mathrm{SE}$ & SD & Mean & $\mathrm{SE}$ & SD \\
\hline & & 0.09 & 0.20 & 109.53 & 0.21 & 0.46 & & 0.21 & 0.46 & 105 & 0.28 & 0.62 \\
\hline$\delta^{13} \mathrm{C} \%{ }_{(\mathrm{VPDB})}$ & -28.18 & 0.12 & 0.26 & -28.26 & 0.02 & 0.05 & -28.10 & 0.05 & 0.12 & -27.88 & 0.04 & 0.08 \\
\hline$\delta^{15} \mathrm{~N} \% \mathrm{o}_{\mathrm{AIR}}$ & +0.76 & 0.25 & 0.56 & +0.04 & 0.10 & 0.23 & +0.24 & 0.13 & 0.29 & +0.38 & 0.42 & 0.93 \\
\hline$[\mathrm{C}]\left(\mathrm{mg} \mathrm{L}^{-1}\right)$ & 16.26 & 0.09 & 0.20 & 17.24 & 0.26 & 0.59 & 15.18 & 1.33 & 2.98 & 15.39 & 0.55 & 1.23 \\
\hline$[\mathrm{N}]\left(\mathrm{mg} \mathrm{L}^{-1}\right)$ & 0.46 & 0.04 & 0.08 & 0.48 & 0.02 & 0.04 & 0.63 & 0.08 & 0.19 & 0.47 & 0.07 & 0.15 \\
\hline
\end{tabular}

TIRI Barleymash results are shown in Table 3. With the exception of the Day 90 frozen sample, all results are within the 1- $\sigma$ limits of the international consensus value of $116.35 \pm 0.008 \mathrm{pMC}$ (Gulliksen and Scott 1995), indicating that there was no leaching of "dead" carbon from the storage containers during the study. 


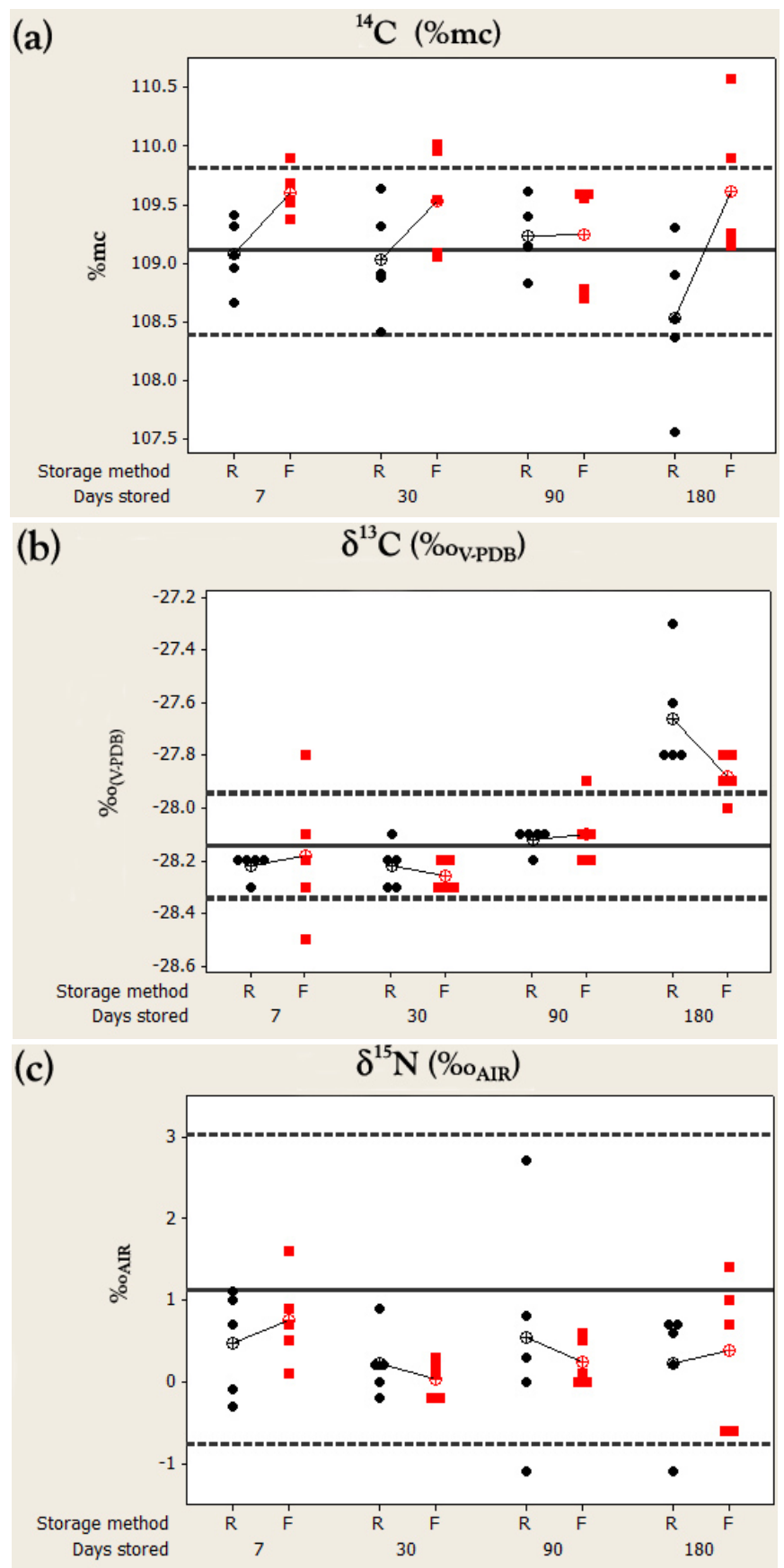

Figure 1 Individual value plots for each determinant versus storage method and storage length: (a) ${ }^{14} \mathrm{C}(\mathrm{pMC})$; (b) $\delta^{13} \mathrm{C}\left(\% \mathrm{ovPDB}_{\mathrm{VPB}}\right)$; (c) $\delta^{15} \mathrm{~N}\left(\% \mathrm{o}_{\mathrm{AIR}}\right)$; (d) [C] $\left(\mathrm{mg} \mathrm{L}^{-1}\right)$; and (e) $[\mathrm{N}]\left(\mathrm{mg} \mathrm{L}^{-1}\right)$. Filled circles represent refrigerated samples and filled squares represent frozen samples. Solid lines show the baseline mean and dashed lines indicate the calculated upper and lower predicted range for the underlying population. 

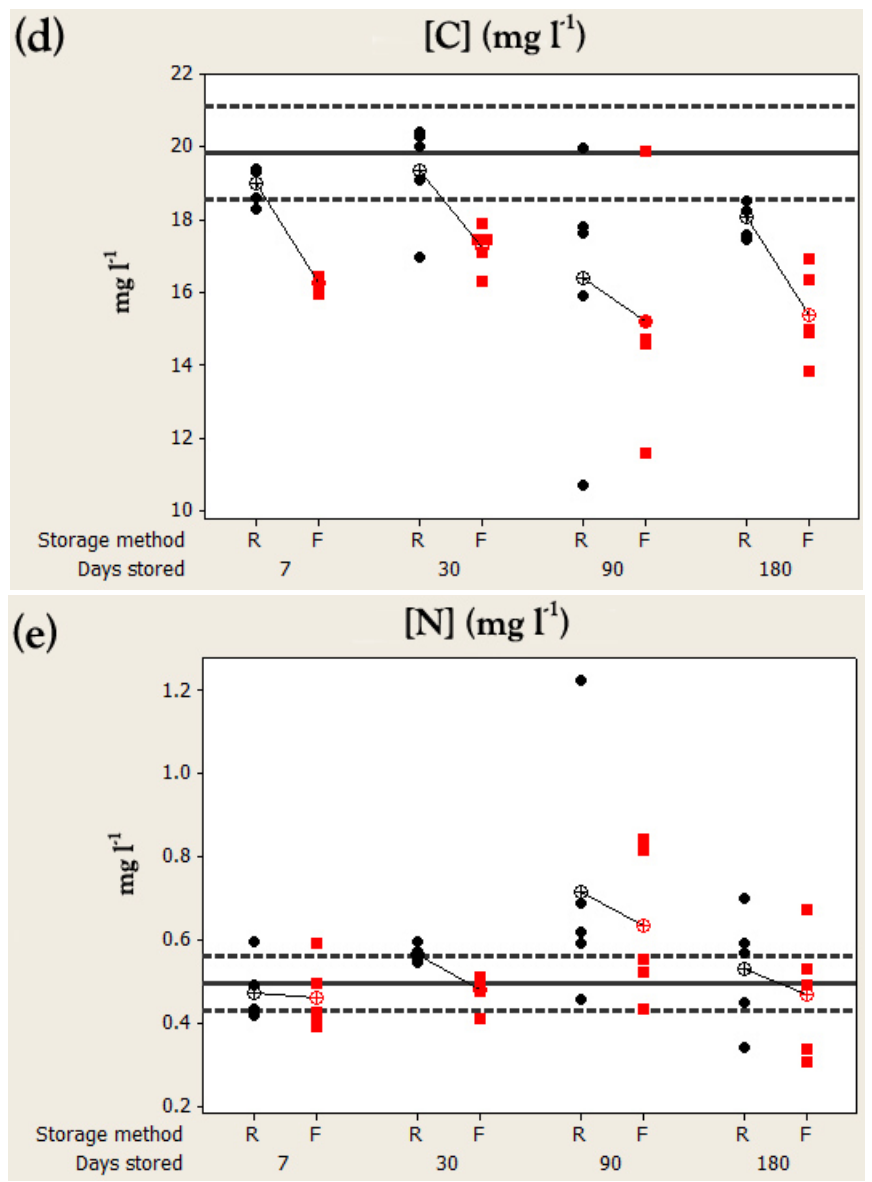

Figure 1 (Continued)

Table 3 Results for TIRI Barley mash.

\begin{tabular}{lcl}
\hline Publication code & ${ }^{14} \mathrm{C}(\mathrm{pMC})$ & ${ }^{13} \mathrm{C} \pm 0.1 \%_{(\mathrm{VPDB})}$ \\
\hline \multicolumn{2}{l}{ Refrigerated distilled water } & \\
SUERC-5215 (Day 7) & $116.73 \pm 0.37$ & -27.0 \\
SUERC-5229 (Day 30) & $116.15 \pm 0.37$ & -27.0 \\
SUERC-6329 (Day 90) & $116.99 \pm 0.36$ & -26.5 \\
SUERC-7440 (Day 180) & $115.99 \pm 0.35$ & -26.5 \\
Frozen distilled water & & \\
SUERC-5214 (Day 7) & $116.71 \pm 0.37$ & -27.0 \\
SUERC-5228 (Day 30) & $116.68 \pm 0.37$ & -26.9 \\
SUERC-6328 (Day 90) & $114.99 \pm 0.36$ & -25.1 \\
SUERC-7205 (Day 180) & $115.51 \pm 0.35$ & -26.3 \\
\hline
\end{tabular}

Based on the assumption that the distribution of determinant values is normal in the baseline population, a prediction interval for a future value from the same population was calculated. The baseline population range was calculated using the baseline mean \pm twice the prediction error. 
Summary statistics and individual data plots for analyses carried out on days 7, 30, 90, and 180 are presented in Table 2 ( $a$ and $b$ ) and Figure 1 (a to e), respectively. Solid lines show the baseline mean and, with the exception of $\delta^{13} \mathrm{C}$, the dashed lines show the calculated upper and lower prediction range expected for the underlying population. For $\delta^{13} \mathrm{C}$, the prediction error was lower than the quoted machine error of $0.1 \%$ and so the dashed line in Figure $1 \mathrm{~b}$ represents twice the machine error.

To determine whether the storage method, the length of storage, or the interaction of storage method and length compromised DOM composition, a general linear model (GLM) (Minitab 15) was fit for each determinant, where $p$ values of $<0.05$ were considered statistically significant. Interaction between storage method and length was shown not to be statistically significant for all determinants and so was removed and the GLM refit. The resulting $F$ and $p$ values are shown in Table 4.

Table 4 General linear model (GLM) results (NS = not statistically significant).

\begin{tabular}{|c|c|c|c|c|c|c|c|c|c|c|}
\hline & \multicolumn{2}{|c|}{$\begin{array}{c}{ }^{14} \mathrm{C} \\
(\mathrm{pMC})\end{array}$} & \multicolumn{2}{|c|}{$\begin{array}{c}\delta^{13} \mathrm{C} \\
\left(\%{ }_{\mathrm{VPDB}}\right)\end{array}$} & \multicolumn{2}{|c|}{$\begin{array}{c}\delta^{15} \mathrm{~N} \\
\left(\%{ }_{\mathrm{AIR}}\right)\end{array}$} & \multicolumn{2}{|c|}{$\begin{array}{c}{[\mathrm{C}]} \\
\left(\mathrm{mg} \mathrm{L}^{-1}\right)\end{array}$} & \multicolumn{2}{|c|}{$\begin{array}{c}{[\mathrm{N}]} \\
\left(\mathrm{mg} \mathrm{L}^{-1}\right)\end{array}$} \\
\hline & $F$ value & $p$ value & $F$ value & $p$ value & $F$ value & $p$ value & $F$ value & $p$ value & $F$ value & $p$ value \\
\hline & & & 22.54 & 0.00 & 0.80 & 050 & 6 & & 111 & 0.01 \\
\hline & 16 & 0 & 1.23 & 0.27 & 0.00 & 0.97 & 50.40 & 0.00 & 1.76 & 0.19 \\
\hline Interaction & NS & NS & NS & NS & NS & NS & NS & NS & NS & NS \\
\hline
\end{tabular}

${ }^{14} \mathrm{C}$ : GLM results showed that storage length is not statistically significant ( $p$ value 0.063 ), but that the storage method is statistically significant $(p=0.001)$. Refrigerated samples appear to have on average lower $\mathrm{pMC}$ values than frozen samples.

Individual subgroups (defined by method and length of storage) were compared to the baseline mean using a 1-sample $t$ test, $p$ values of $<0.01$ were considered statistically significant (adjusting for multiple comparisons). Results (see Table 5) show that, with the exception of the Day 7 frozen samples, the mean for each group was statistically indistinguishable from the baseline mean. For both storage methods, samples stored for 180 days give results that did not overlap at 2- $\sigma$ limits with the predicted baseline population range (Figure 1a). We suggest therefore that samples stored for long periods of time are subject to increased variability.

Table 5 One-sample $t$ test.

\begin{tabular}{|c|c|c|c|c|c|c|c|c|c|c|}
\hline \multirow[b]{2}{*}{$\begin{array}{l}\text { Days } \\
\text { stored }\end{array}$} & \multicolumn{5}{|c|}{ Refrigerated sample $p$ values } & \multicolumn{5}{|c|}{ Frozen samples $p$ values } \\
\hline & $\begin{array}{l}{ }^{14} \mathrm{C} \\
(\mathrm{pMC})\end{array}$ & $\begin{array}{l}\delta^{13} \mathrm{C} \\
\left(\%{ }_{\text {VPDB }}\right)\end{array}$ & $\begin{array}{l}\delta^{15} \mathrm{~N} \\
\left(\% 0_{\mathrm{AIR}}\right)\end{array}$ & $\begin{array}{l}{[\mathrm{C}]} \\
\left(\mathrm{mg} \mathrm{L}^{-1}\right)\end{array}$ & $\begin{array}{l}{[\mathrm{N}]} \\
\left(\mathrm{mg} \mathrm{L}^{-1}\right)\end{array}$ & $\begin{array}{l}{ }^{14} \mathrm{C} \\
(\mathrm{pMC})\end{array}$ & $\begin{array}{l}\delta^{13} \mathrm{C} \\
\left(\%{ }_{\mathrm{VPDB}}\right)\end{array}$ & $\begin{array}{l}\delta^{15} \mathrm{~N} \\
\left(\% 0_{\mathrm{AIR}}\right)\end{array}$ & $\begin{array}{l}{[\mathrm{C}]} \\
\left(\mathrm{mg} \mathrm{L}^{-1}\right)\end{array}$ & $\begin{array}{l}{[\mathrm{C}]} \\
\left(\mathrm{mg} \mathrm{L}^{-1}\right)\end{array}$ \\
\hline 7 & 0.84 & 0.02 & 0.09 & 0.02 & 0.53 & 0.01 & 0.75 & 0.22 & 0.00 & 0.41 \\
\hline 30 & 0.71 & 0.10 & 0.01 & 0.51 & 0.00 & 0.11 & 0.01 & 0.00 & 0.00 & 0.44 \\
\hline 90 & 0.43 & 0.37 & 0.41 & 0.09 & 0.17 & 0.56 & 0.51 & 0.00 & 0.03 & 0.17 \\
\hline 180 & 0.12 & 0.01 & 0.06 & 0.00 & 0.62 & 0.15 & 0.00 & 0.15 & 0.00 & 0.70 \\
\hline
\end{tabular}

$\delta^{13} \mathbf{C}$ : GLM results show that the storage length effect has a statistically significant effect $(p=0.00)$, while storage method is not statistically significant $(p=0.27)$. It appears that $\delta^{13} \mathrm{C}$ increases on average with increasing storage time. Individual refrigerated and frozen $\delta^{13} \mathrm{C}$ of samples stored up to 90 days are within 1- and 2- $\sigma$ limits, respectively, of the baseline mean $\pm 0.1 \%$. Day 180 refrigerated samples gave 2 results that did not overlap at $\pm 0.2 \%$ with the predicted baseline population range (Figure 1b) and again we suggest that lengthy storage may cause increased variability in the samples. 
$\delta^{15} \mathrm{~N}$ : GLM results for $\delta^{15} \mathrm{~N}_{\mathrm{TDN}}$ showed neither storage length nor storage method cause statistically significant changes in sample $\delta^{15} \mathrm{~N}_{\mathrm{TDN}}$. The bulk of $\delta^{15} \mathrm{~N}_{\mathrm{TDN}}$ variation was attributed to the length of storage ( $F$ values of 0.80 and 0.00 , respectively). While the majority of the results plot below the mean $\delta^{15} \mathrm{~N}_{\mathrm{TDN}}$ baseline, all individual analyses lie (Figure 1c) within the 1- $\sigma$ confidence limits for the calculated range. Thus, we cannot say these samples are statistically different from baseline samples.

[C]: GLM results show statistically significant effects of storage method $(p=0.03)$ and storage length $(p=0.00)$ for this determinant. This is supported by results from a 1-sample $t$ test comparing individual subgroups (defined by method and length of storage) to the baseline mean; $p$ values of $<0.01$ were considered statistically significant (Table 5 ). From this, it can be seen that only subgroups Day 7, 30, and 90 (refrigerated) and Day 90 (frozen) were statistically indistinguishable from the baseline mean.

From Figure 1d, it can be seen that values from both storage methods are very variable with individual [C] values ranging from 10.7 to $20.4 \mathrm{mg} \mathrm{L}^{-1}$. There is an apparent decrease in carbon concentration with time. Values for frozen samples are consistently lower than those refrigerated and, with the exception of 1 sample from Day 90, always fall below the predicted range for the baseline population. Given that this storage method should cause the least DOC respiration, we hypothesize that the reduction in $[\mathrm{C}]$ is due to changes in the structure of the DOC caused by freezing, e.g. the formation of colloids, sufficiently large to be retained by the GF/F during filtering. This suggests that samples should be filtered prior to storing frozen. Unfortunately, we did not realize this process may be significant at the time of analyses and so did not process nor retain the filter papers to generate data to test this theory.

Additionally, our experience is that $[\mathrm{C}]$ can still be lower in frozen samples that have been filtered than the refrigerated filtered equivalent (S Waldron, unpublished data). Thus, we suggest that where $[\mathrm{C}]$ is important, samples are not stored frozen and if to be refrigerated for longer than 30 days, are prefiltered.

[N]: GLM results shows that the storage method $(p=0.19)$ effect is not statistically significant, but the storage length effect $(p=0.01)$ is statistically significant. Individual subgroups (defined by method and length of storage) were compared to the baseline mean using a 1-sample $t$ test, where $p$ values of $<0.01$ were considered statistically significant. Results (see Table 5) show that, with the exception of the Day 30 refrigerated sample, the mean for each group was statistically indistinguishable from the baseline mean.

\section{CONCLUDING REMARKS}

There is a statistically significant storage length effect for [C]. Despite this, storage length (up to 180 days) does not have a statistically significant effect on ${ }^{14} \mathrm{C}$ and $\delta^{13} \mathrm{C}$ results, implying that the carbon isotopic composition of $\mathrm{C}$ lost from the DOM (inferred due to the formation of larger particles by colloid participation or particle absorption) has the same isotopic composition as the bulk sample DOM remaining.

Determinants analyzed in this study were collected from a headwater stream draining a peatland catchment, where the sample matrix is likely dominated by humics. It is possible that the observation presented here is unique to this site or catchment type. Unfortunately, this experiment is insufficiently wide-ranging to allow us to comment on how generic this observation may be, and it may be inappropriate to assume a similar response may occur in samples collected from a different catchment type. 
Statistically significant changes may occasionally be of little practical relevance (e.g. very small changes while statistically significant may be considerably less than practically relevant changes), for example, in cases where field sample composition is likely to show larger changes during the field experimental period, e.g. the impact of large-scale tree felling on a nearby oligotrophic lake.

In conclusion, it would appear from this study that for storage periods of up to 180 days, both refrigeration and freezing are suitable storage methods for analysis of ${ }^{14} \mathrm{C}(\mathrm{pMC}), \delta^{13} \mathrm{C}\left(\%{ }_{\mathrm{VPDB}}\right), \delta^{15} \mathrm{~N}$ $\left(\%{ }_{\mathrm{AIR}}\right)$, and $\% \mathrm{~N}\left(\mathrm{mg} \mathrm{L}^{-1}\right)$ in freshwater samples. In studies where $\% \mathrm{C}\left(\mathrm{mg} \mathrm{L}^{-1}\right)$ values are necessary, samples should be filtered upon collection, refrigerated, and if possible, analyzed within 30 days. As DOC can be adsorbed onto particulate organic carbon, and the proportion of both pool sizes can change with hydraulic regime (likely during the course of a prolonged field campaign) (e.g. Dawson et al. 2004), sample filtration prior to storage would seem the best practice to minimize differential DOC losses and integrity of $\% \mathrm{C}\left(\mathrm{mg} \mathrm{L}^{-1}\right)$.

\section{ACKNOWLEDGMENTS}

SW was funded by a Natural Environment Research Council Advanced Fellowship NER/J/S/2001/ 00793. ${ }^{14} \mathrm{C}$ analysis were funded by $\mathrm{NRCF}(\mathrm{E})$ allocation $1058.1003 .{ }^{15} \mathrm{~N}$ and $[\mathrm{N}]$ analyses were undertaken at the Scottish Universities Research and Reactor Centre. Thanks is extended to Mr L Chalmers for his work on sample preparation.

\section{REFERENCES}

Ahad JME, Barth JAC, Ganeshram RS, Spencer RGM, Uher G. 2008. Controls on carbon cycling in two contrasting temperate zone estuaries: the Tyne and Tweed, UK. Estuarine, Coastal and Shelf Science 78(4):68593.

Amon RMW, Meon B. 2004. The biogeochemistry of dissolved organic matter and nutrients in two large Arctic estuaries and potential implications for our understanding of the Arctic Ocean system. Marine Chemistry 92(1-4):311-30.

Battin TJ, Kaplan LA, Findlay S, Hopkinson CS, Marti E, Packman AI, Newbold JD, Sabater F. 2008. Biophysical controls on organic carbon fluxes in fluvial networks. Nature Geoscience 1:95-100.

Boutton TW, Wong WW, Hachey DL, Lee LS, Cabrera MP, Klein PD. 1983. Comparison of quartz and pyrex tubes for combustion of organic samples for sample carbon isotope analysis. Analytical Chemistry 55(11): 1832-3.

Coplen TB. 1994. Reporting of stable hydrogen, carbon and oxygen isotopic abundances. Pure and Applied Chemistry 66(2):273-6.

Craig H. 1957. Isotopic standards for carbon and oxygen and correction factors for mass-spectrometric analysis of carbon dioxide. Geochemica et Cosmochemica Acta 12(1-2):133-49.

Dawson JJC, Billett MF, Hope D, Palmer SM, Deacon CM. 2004. Sources and sinks of aquatic carbon in a peatland stream continuum. Biogeochemistry 70(1): 71-92.

Evans CD, Freeman C, Cork LG, Thomas DN, Reynolds B, Billett MF, Garnett MH, Norris D. 2007. Evidence against recent climate-induced destabilisation of soil carbon from ${ }^{14} \mathrm{C}$ analysis of riverine dissolved organic matter. Geophysical Research Letters 34: L07407, doi:10.1029/2007GL029431.

Freeman C, Evans CD, Monteith DT, Reynolds B, Fenner N. 2001. Export of organic carbon from peat soils. Nature 412(6849):785.

Freeman S, Bishop P, Bryant C, Cook G, Dougans D, Ertunc T, Fallick A, Ganeshram R, Maden C, Naysmith P, Schnabel C, Scott M, Summerfield M, Xu S. 2007. The SUERC AMS laboratory after 3 years. Nuclear Instruments and Methods in Physics Research $B$ 259(1):66-70.

Griffith DR, Barnes RT, Raymond PA. 2009. Inputs of fossil carbon from wastewater treatment plants to U.S. rivers and oceans. Environmental Science \& Technology 43(15):5647-51.

Gulliksen R, Scott EM. 1995. Report of the TIRI workshop, Saturday 13th August 1994. Radiocarbon 37(2): 820-1.

Hope D, Billett MF, Milne R, Brown TAW. 1997. Exports of organic carbon in British waters. Hydrological Processes 11(3):325-44.

Lobbes JM, Fitznar HP, Kattner G. 2000. Biogeochemical characteristics of dissolved and particulate organic matter in Russian rivers entering the Arctic Ocean. Geochimica et Cosmochimica Acta 64(17): 2973-83.

Montieth DT, Stoddard JL, Evans CD, de Wit HA, Forsius M, Hogasen T, Wilander A, Skjelkvale BL, Jefferies DS, Vuorenmaa J, Keller B, Kopacek J, Vesely J. 2007. Dissolved organic carbon trends resulting 
from changes in atmospheric deposition chemistry. Nature 450(7169):537-40.

Mook WG, van der Plicht J. 1999. Reporting ${ }^{14} \mathrm{C}$ activities and concentrations. Radiocarbon 41(3):227-39.

Norra S, Handley LL, Berner Z, Stuben D. $2005 .{ }^{13} \mathrm{C}$ and ${ }^{15} \mathrm{~N}$ natural abundances of urban soils and herbaceous vegetation in Karlsruhe, Germany. European Journal of Soil Science 56(5):607-20.

Raymond PA, Bauer JE. 2001. Use of ${ }^{14} \mathrm{C}$ and ${ }^{13} \mathrm{C}$ natural abundances for evaluating riverine, estuarine and coastal DOC and POC sources and cycling: a review and synthesis. Organic Geochemistry 32(4):469-85.

Stuiver M, Polach HA. 1977. Discussion: reporting of ${ }^{14} \mathrm{C}$ data. Radiocarbon 19(3):355-63.

Thompson DBA, Gordon JE, Horsfiled D. 2001. Montane landscapes in Scotland: Are these natural arte- facts or complex relicts? In: Gordon J, Leys K, editors. Earth Science and the Natural Heritage. London: Stationary Office. p 105-19.

Waldron S, Flowers H, Arlaud C, Bryant CLB, McFarlane S. 2009. The significance of organic carbon and nutrient export from peatland-dominated landscapes subject to disturbance, a stoichiometric perspective. Biogeosciences 6:363-74.

Xu S, Anderson R, Bryant CL, Gook GT, Douglas A, Freeman S, Naysmith P, Schnabel C, Scott EM. 2004. Capabilities of the new SUERC 5MV AMS Facility for ${ }^{14} \mathrm{C}$ dating. Radiocarbon 46(1):59-64.

Zeigler SE, Fogel ML. 2003. Seasonal and diel relationships between the isotopic compositions of dissolved and particulate organic matter in freshwater ecosystems. Biogeochemistry 64(1):25-52. 